\title{
The elusive search for stable risk preferences
}

\author{
Craig R. Fox ${ }^{1,2 *}$ and David Tannenbaum ${ }^{1}$ \\ 1 Anderson School, University of California Los Angeles, Los Angeles, CA, USA \\ 2 Department of Psychology, University of California Los Angeles, Los Angeles, CA, USA \\ *Correspondence: cfox@anderson.ucla.edu
}

In the early morning hours of June 20, 2011 Ryan Dunn was driving his Porsche 911 GTE up to 140 miles per hour through the Pennsylvania countryside. The car careened over a guardrail and into a wooded area, killing Dunn and a passenger in a fiery crash. A toxicology report later determined that Dunn's blood alcohol level was more than twice the legal limit. Many observers found the accident somewhat unsurprising because Dunn was best known for performing dangerous stunts in the popular Jackass television and movie series. As one blogger put it: "This is the type of person he was. He was a risk-taker". Indeed, the headline in the Philadelphia Daily News later read: "Dunn deal: Death of a risk-taker."

The public's response to the Ryan Dunn tragedy illustrates a prevalent belief that there are consistent individual differences in not only people's risk-taking behavior but also in their underlying appetite for risk. Several industries depend on this assumption. For instance, in financial services the "suitability doctrine" legally requires financial advisors to assess their clients' risk preference before dispensing advice (Mundheim, 1965). Likewise, most socialscience disciplines traditionally assume stable and measurable individual differences in risk preference. However, based on our reading of the empirical literature, the common intuition that risk preference is a stable disposition may reflect more of an attribution error than empirical fact.

\section{FOUR CHALLENGES TO ESTABLISHING STABLE RISK PREFERENCES}

To date, most laboratory measurements of risk preference either fail to adequately predict naturalistic risk-taking or are difficult to interpret. A sparse literature in economics using choices among chance gambles has had only modest success predicting

${ }^{1}$ http://mydisenchantedlife.wordpress.com/ 2011/06/27/dunn-lived-a-risky-life/ some forms of naturalistic risk-taking (e.g., Barsky et al., 1997; Pennings and Smidts, 2000; Brown et al., 2006; Jaeger et al., 2010) and there are even some published failures (Brockhaus, 1980; Dohmen et al., 2005). For instance, Dohmen et al. found that willingness to invest in a hypothetical chance lottery predicted some forms of naturalistic risk-taking, but just as often yielded null effects - and furthermore, was less predictive than a single self-reported measure of general risk-propensity. We suspect that other failed studies have landed in file drawers. Even careful attempts to measure parameters of prospect theory (Kahneman and Tversky, 1979; Tversky and Kahneman, 1992), the leading behavioral model of decision under risk, have yielded disappointing results, both in terms of test-retest reliability (Zeisberger et al., 2011) and prediction of choices among laboratory-constructed investments (Erner et al., 2009).

In contrast to economic measures of risk preference, some measures devised by clinical psychologists such as the Balloon Analog Risk Task (BART) and Iowa gambling task (IGT) have had moderate success in predicting naturalistic risk-taking. For instance, the BART involves pressing a button to insert puffs of air in a visually depicted balloon; each puff adds a fixed amount of money to an account, but if the balloon explodes before the participant cashes out, she receives nothing. Risk tolerance in these tasks has successfully predicted such behaviors as drug use, unprotected sex, gambling, and stealing (e.g., Bechara et al., 2001; Lejuez et al., 2002). Although these results are encouraging, such clinical tasks are not readily decomposable into basic cognitive and economic constructs that allow for a clear interpretation of risk preference (Schonberg et al., 2011).

We suggest that the elusiveness of stable and measurable risk preferences arises from a variety of conceptual and methodological challenges, including: (1) clearly defining risk and risk-taking; (2) segregating risk preference from other contributors to risk-taking; (3) differentiating risk preference from related traits; and (4) accounting for situational influences on risk preference.

\section{CHALLENGE 1: DEFINING RISK AND RISK- TAKING}

A first challenge in identifying stable risk preferences is that different disciplines define risk - and therefore risk-taking - in different ways. The economics and finance literatures usually define risk in terms of variance in the probability distribution over possible outcomes (e.g., Markowitz, 1952). Thus, for economists, risk-seeking means a preference for a higher-variance payoff, holding expected value constant. In contrast, when clinicians and laypeople identify behaviors as "risky," they invoke a broader meaning of the term. Behaviors such as drug use, drunk driving, stealing, unprotected sex, and hang gliding are often thought of as risky because such behaviors can result in loss or harm to oneself or others (e.g., Furby and Beyth-Marom, 1992). Likewise, interviews with experienced managers suggest that they also construe risk in terms of exposure to possible negative outcomes, rather than variance over outcomes or some other quantifiable construct (March and Shapira, 1987). Psychometric studies have further found that that the lay conception of riskiness encompasses a dread dimension characterized by lack of control or potential catastrophic consequences, and an unknown dimension characterized by unobservable, unknown, or delayed consequences (Slovic, 1987). We note that an advantage of the economic conception of risk is that it is simple and easy to parameterize; a disadvantage is that it does not appear to coincide with natural intuitions of most risk-takers.

\section{CHALLENGE 2: DISTILING RISK PREFERENCE}

Even if one accepts a particular definition of risk, another challenge is distinguishing risk preference from other direct contributors to risk-taking. A person may take on more 
or less risk than his underlying preference would dictate (e.g., climbing a dangerous rock face) for a number of reasons. First, risk-taking could be a side-effect of pursuing an independent goal such as social approbation (e.g., responding to peer pressure) or enhancing one's self-image (e.g., a first ascent of a new route). Second, risk perception may drive behavior independently of risk preference. For instance, a climber may simply underestimate or ignore the risk. Indeed, although studies have found substantial variation in individual risktaking across life domains, such differences can be attributed largely to variation in the perceived risks and/or benefits of such activities (Weber et al., 2002; Hanoch et al., 2006). Third, risk-taking behavior could reflect a tendency to heavily discount future consequences that are accurately perceived (e.g., favoring the immediate pleasure of smoking over possible long-term health consequences).

\section{CHALLENGE 3: DIFFERENTIATING RISK PREFERENCE}

Even if one distinguishes risk preference from other direct contributors to risktaking, this construct must be differentiated from related traits that also predict risk-taking. One trait that has been widely linked to risky behavior is sensation-seeking, the need for "varied, novel, complex, and intense sensations and experiences, and the willingness to take physical, social, legal, and financial risks for the sake of such experiences"(Zuckerman, 2007, p. 49). As this definition makes clear, sensation-seeking involves a tolerance for risk; what is less clear is the extent that risk preferences are independent of sensation-seeking drives. A second related construct is impulsivity, marked by tendencies to engage in rash action and difficulty in inhibiting impulses - not surprisingly, these characteristics are also associated with risky behaviors (Steinberg et al., 2008). Third, appetitive and inhibitory drives (e.g., as measured by the BIS/BAS scale of Carver and White, 1994) appear to predict risk-taking (Demaree et al., 2008). To our reading of the literature, the relationships between these measures and an underlying appetite for risk have not yet been resolved satisfactorily. For instance, some of the aforementioned constructs may be causal antecedents to risk preference; others may moderate the relationship between risk preference and risk-taking. Furthermore, some items in these scales explicitly involve naturalistic risk-taking or risk preference (e.g., "I think I would enjoy the sensations of skiing very fast down a high mountain slope" in the sensation-seeking scale; "I am a cautious person" on the Whiteside and Lynam, 2001 impulsivity scale). Mapping out these relationships will be necessary for establishing the construct validity of any measure of risk preference.

\section{CHALLENGE 4: SITUATIONAL INFLUENCES ON RISK PREFERENCE}

Even if risk preference can be differentiated from related traits, there may be inherent limits to the proportion of variance in naturalistic risk-taking that can be explained by such a measure. This is because a number of situational variables cause even simple economic expressions of risk preference to fluctuate.

First, risk preferences change systematically with reference points such as aspiration levels. People tend to be risk-averse for gains and risk-seeking for losses of moderate to high probability (the reverse is true for low probabilities; Kahneman and Tversky, 1979; Tversky and Kahneman, 1992). Thus, they tend to be more risk-seeking when striving to reach a goal (Larrick et al., 2009) or avoid losing money (Payne et al., 1980). Moreover, past history can influence risktaking - for instance people tend to be more risk-seeking after experiencing gains (when gambling with "house money"; Thaler and Johnson, 1990).

Second, risk preferences vary systematically with normatively irrelevant features of the choice environment. Examples include whether options are described in terms of potential gains or losses (Tversky and Kahneman, 1986), how they are labeled (e.g., as an "insurance policy" or "gamble"; Hershey et al., 1982), how they are measured (e.g., through pricing gambles or choosing among them, Lichtenstein and Slovic, 1971; Harbaugh et al., 2010), and the nature of contrasting risks (e.g., adding a "decoy" gamble can increase the attractiveness of a dominating gamble; Huber et al., 1982).

Third, risk preferences can fluctuate systematically with the decision maker's transitory state of mind. State variables that influence risk preferences include specific emotions (e.g., anger versus fear; Lerner and
Keltner, 2001), level of arousal (Mano, 1994; Knutson et al., 2008), motivational state (e.g., aspirational versus protective focus; Scholer et al., 2010), feelings of security (Levav and Argo, 2010), and momentarilyactivated identities (Morris et al., 2008).

\section{SOME REASONS FOR OPTIMISM}

Despite these substantial challenges, there are reasons to believe that researchers may establish relatively stable risk preferences - or at least reasonably good prediction of future risk-taking - in the years to come.

First, risk preferences elicited using chance gambles show systematic differences across demographic groups such as age, gender, and race (e.g., Barsky et al., 1997; Byrnes et al., 1999; Donkers et al., 2001), suggesting cultural and/or biological antecedents. Indeed, there appear to be genetic correlates of risk preference. For example, there is greater convergence in economic risk preferences among identical twins than fraternal twins raised together, accounting for roughly $20 \%$ of the variation in risk-taking behavior (Cesarini et al., 2009). Genetic markers related to dopamine and serotonin transmission have also been linked to economic and financial risk preferences in the lab, as have baseline levels of testosterone (Dreber et al., 2009; Kuhnen and Chiao, 2009; Stanton et al., 2011).

Second, state variables that influence risk preference often have stable dispositional counterparts. For instance, in addition to the finding that induced anger (fear) leads to more (less) risk-seeking, researchers have found that chronic levels of anger and fear have similar associations with risk-taking (Lerner and Keltner, 2001).

Finally, it may be that some stable individual differences are masked by their predictable interaction with situation variables. For instance, individuals with higher scores on the Cognitive Reflection Test tend to be more risk-seeking for gains and less riskseeking for losses (Frederick, 2005). Better characterization of such interactions may improve prediction of risk-taking behavior (Figner and Weber, 2011).

\section{WHERE DO WE GO FROM HERE?}

To our reading, the elusive search for stable risk preferences has found mixed support. On one hand, there has been modest success identifying predictable differences between 
individuals in risk-taking; on the other hand, there remain substantial theoretical challenges to establishing stable risk preferences. Further research should:(a) define risk in a way that is crisp yet resonates with lay intuitions, (b) distill risk preference from other contributors to risk-taking, (c) model the relationship of risk preference to related traits, and (d) account for the situational factors that cause risk preferences to fluctuate.

This theoretical work will require innovations in measurement of risk preference. Following Schonberg et al. (2011), we believe that future measurement paradigms must be: (1) predictively valid, (2) readily decomposable into basic cognitive and/or economic constructs, and (3) dynamic and affectively engaging. This work may also be supported by brain imaging and other physiological measurement methods.

This last criterion merits further comment. Perhaps clinical measures of risk preference better predict naturalistic risk-taking than economic measures because they better capture the escalating tension and exhilaration that accompany risky pursuits. Some researchers have argued that anticipatory emotions are crucial contributors to risk-taking, yet have been largely ignored by traditional decision-theoretic models (Loewenstein et al., 2001). Paradigms that capture the dynamic and affective nature of risk may improve our ability to predict risk-taking and help us understand its psychological sources.

\section{ACKNOWLEDGMENTS}

We thank Tom Schonberg for helpful comments on an earlier draft of this paper. This research was supported by the United States Department of Homeland Security through the National Center for Risk and Economic Analysis of Terrorism Events (CREATE) under award number 2010-ST-061-RE0001. However, any opinions, findings, and conclusions or recommendations in this document are those of the authors and do not necessarily reflect views of the United States Department of Homeland Security, or the University of Southern California, or CREATE.

\section{REFERENCES}

Barsky, R. B., Juster, F. T., Kimball, M. S., and Shapiro, M. D. (1997). Preference parameters and behavioral heterogeneity: an experimental approach in the Health and Retirement Study. Q. J. Econ. 112, 537-579.
Bechara, A., Dolan, S., Denburg, N., Hindes, A., Anderson, S. W., and Nathan, P.E. (2001). Decision-making deficits, linked to a dysfunctional ventromedial prefrontal cortex, revealed in alcohol and stimulant abusers. Neuropsychologia 39, 376-389.

Brockhaus, R.H. (1980). Risk-taking propensity of entrepreneurs. Acad. Manage. J. 23, 509-520.

Brown, S., Farrell, L., Harris, M., and Sessions, J. (2006). Risk preference and employment contract type. J. R. Stat. Soc. Ser. A Stat. Soc. 169, 849-863.

Byrnes, J. P., Miller, D. C., and Schafer, W. D. (1999). Gender differences in risk-taking: a meta-analysis. Psychol. Bull. 125, 367-383.

Carver, C. S., and White, T. L. (1994). Behavioral inhibition, behavioral activation, and the affective responses to impending reward and punishment: the BIS/BAS scales. J. Pers. Soc. Psychol. 67, 319-333.

Cesarini, D., Dawes, C. T., Johannesson, M., Lichtenstein, P., and Wallace, B. (2009). Genetic variation in preferences for giving and risk-taking. Q. J. Econ. 124, 809-842.

Demaree, H. A., DeDonno, M. A., Burns, K. J., and Everhart, D. E. (2008). You bet: how personality differences affect risk-taking preferences. Pers. Individ. Dif. 44, 1484-1494.

Dohmen, T., Falk, A., Huffman, D., Sunde, U., Schupp, J., and Wagner, G. G. (2005). Individual Risk Attitudes: New Evidence From a Large, Representative, Experimentally-Validated Survey. IZA Discussion Paper, No. 1730.

Donkers, B., Melenberg, B., and Van Soest, A. (2001). Estimating risk attitudes using lotteries: a large sample approach. J. Risk Uncertain. 22, 165-195.

Dreber, A., Apicella, C. L., Eisenberg, D. A., Garcia, J. R., Zamore, R. S., Lum, J. K., and Campbell, B. (2009). The 7R polymorphism in the dopamine receptor D4 gene (DRD4) is associated with financial risk-taking in men. Evol. Hum. Behav. 30, 85-92.

Erner, C., Klos, A., and Langer, T. (2009). Can Prospect Theory be Used to Predict Investor's Willingness to Pay? University of Muenster, Muenster, Germany.

Figner, B., and Weber, E. U. (2011). Who takes risks when and why? Determinants of risk taking. Curr. Dir. Psychol. Sci. 20, 211-216.

Frederick, S. (2005). Cognitive reflection and decision making. J. Econ. Perspect. 19, 25-42.

Furby, L., and Beyth-Marom, R. (1992). Risk taking in adolescence: a decision-making perspective. Dev. Rev. 12, 1-44.

Hanoch, Y., Johnson, J. G., and Wilke, A. (2006). Domain specificity in experimental measures and participant recruitment. Psychol. Sci. 17, 300-304.

Harbaugh, W. T., Krause, K., and Vesterlund, L. (2010). The fourfold pattern of risk attitudes in choice and pricing tasks. Econ. J. 120, 595-611.

Hershey, J. C., Kunreuther, H. C., and Schoemaker, P. J. H (1982). Sources of bias in assessment procedures for utility functions. Manage. Sci. 28, 936-954.

Huber, J., Payne, J. W., and Puto, C. (1982). Adding asymmetrically dominated alternatives: violations of regularity and the similarity hypothesis. J. Consum. Res. 9 , 90-98.

Jaeger, D. A., Dohmen, T., Falk, A., Huffman, D. Sunde, U., and Bonin, H. (2010). Direct evidence on risk attitudes and migration. Rev. Econ. Stat. 92, 684-689.
Kahneman, D., and Tversky, A. (1979). Prospect theory: an analysis of decisions under risk. Econometrica 47, 263-291.

Knutson, B., Wimmer, G. E., Kuhnen, C. M., and Winkielman, P. (2008). Nucleus accumbens activation mediates the influence of reward cues on financial risk-taking. Neuroreport 19, 509-513.

Kuhnen, C. M., and Chiao, J.Y. (2009). Genetic determinants of financial risk-taking. PLoS ONE4, e4362. doi: 10.1371/journal.pone.0004362

Larrick, R. P., Heath, C., and Wu, G. (2009). Goal-induced risk taking in negotiation and decision making. Soc. Cogn. 27, 342-364.

Lejuez, C. W., Read, J. P., Kahler, C. W., Richards, J. B., Ramsey, S. E., Stuart, G. L., Strong, D. R., and Brown, R. A. (2002). Evaluation of a behavioral measure of risk-taking: the balloon analogue risk task (BART). J. Exp. Psychol. Appl. 8, 75-84.

Lerner, J. S., and Keltner, D. (2001). Fear, anger, and risk. J. Pers. Soc. Psychol. 81, 146-159.

Levav, J., and Argo, J. (2010). Physical contact and financial risk-taking. Psychol. Sci. 21, 804-810.

Lichtenstein, S., and Slovic, P. (1971). Reversals of preference between bids and choices in gambling decisions. J. Exp. Psychol. 89, 46-55.

Loewenstein, G. F., Weber, E. U., Hsee, C. K., and Welch, N. (2001). Risk as feelings. Psychol. Bull. 127, 267-286.

Mano, H. (1994). Risk-taking, framing effects, and affect. Organ. Behav. Hum. Decis. Process. 57, 38-58.

March, J. G., and Shapira, Z. (1987). Managerial perspectives on risk and risk-taking. Manage. Sci. 33, 11, 1404-1418.

Markowitz, H. (1952). Portfolio selection. J. Finance 7, 77-91.

Morris, M. W., Carranza, E., and Fox, C. R. (2008). Mistaken identity: activating conservative political identities induces "conservative" financial decisions. Psychol. Sci. 19, 1154-1160.

Mundheim, R. H. (1965). Professional responsibilities of broker-dealers: the suitability doctrine. Duke Law J. 3, 445-480.

Payne, J., Laughunn, D., and Crum, R. (1980). Translation of gambles and aspiration level effects in risky choice behavior. Manage. Sci. 26, 1039-1060.

Pennings, J. M. E., and Smidts, A. (2000). Assessing the construct validity of risk attitude. Manage. Sci. 46, 10, 1337-1348.

Scholer, A., Zou, X., Fujita, K., Stroessner, S. J., and Higgins, E.T.(2010). When risk seeking becomes a motivational necessity. J. Pers. Soc. Psychol. 99, 215-231.

Schonberg, T., Fox, C. R., and Poldrack, R. A. (2011). Mind the gap: bridging economic and naturalistic risk-taking with cognitive neuroscience. Trends Cogn. Sci. (Regul. Ed.) 15, 11-19.

Slovic, P. (1987). Perception of risk. Science 236, 280-285. Stanton, S. J., Mullette-Gillman, A. M., McLaurin, R. E., Kuhn, C. M., LaBar, K. S., Platt, M. L., and Huettel, S. A. (2011). Low- and high-testosterone individual exhibit decreased aversion to economic risk. Psychol. Sci. 22, 447-453.

Steinberg, L., Albert, D., Cauffman, E., Banich, M., Graham, S., and Woolard, J. (2008). Age differences in sensation-seeking and impulsivity as indexed by behavior and self-report: evidence for a dual systems model. Dev. Psychol. 44, 1764-1778.

Thaler, R. H., and Johnson, E. J. (1990). Gambling with the house money and trying to break even: the effects of prior outcomes on risky choice. Manage. Sci. 36, 643-660. 
Tversky, A., and Kahneman, D. (1986). Rational choice and the framing of decisions. J. Bus. 59, 251-278.

Tversky, A., and Kahneman, D. (1992). Advances in prospect theory: cumulative representation of uncertainty. J. Risk Uncertain. 5, 297-323.

Weber, E. U., Blais, A. R., and Betz, N. E. (2002). A domain-specific risk-attitude scale: measuring risk perceptions and risk behaviors. J. Behav. Decis. Mak. 15, 263-290.

Whiteside, S. P., and Lynam, D. R. (2001). The five factor model and impulsivity: using a structural model of personality to understand impulsivity. Pers. Individ. Dif. 30, 669-689.

Zeisberger, S., Vrecko, D., and Langer, T. (2011). Measuring the time stability of prospect theory preferences. Theory Decis. doi: 10.1007/s11238-010-9234-3.

Zuckerman, M. (2007). Sensation-Seeking and Risk. Washington, DC: American Psychological Association.

Received: 13 July 2011; accepted: 11 October 2011; published online: 15 November 2011.
Citation: Fox CR and Tannenbaum D (2011) The elusive search for stable risk preferences. Front. Psychology 2:298. doi: 10.3389/fpsyg.2011.00298

This article was submitted to Frontiers in Cognition, a specialty of Frontiers in Psychology.

Copyright ( 12011 Fox and Tannenbaum. This is an openaccess article subject to a non-exclusive license between the authors and Frontiers Media SA, which permits use, distribution and reproduction in other forums, provided the original authors and source are credited and other Frontiers conditions are complied with. 